\title{
a: eResearch
}

eResearch: the open access repository of the research output of Queen Margaret University, Edinburgh

This is publisher-formatted version of a document published as:

Hewlett, Nigel and Rendall, Monica (1998) Rural versus urban accent as an influence on the rate of speech. Journal of the International Phonetic Association, 28 (1-2). pp. 63-71. ISSN ISSN: 0025-1003 EISSN: 14753502

Accessed from:

http://eresearch.qmu.ac.uk/2564/

The published version is available online at:

http://dx.doi.org/10.1017/S0025100300006253

\section{Repository Use Policy}

The full-text may be used and/or reproduced, and given to third parties for personal research or study, educational or not-for-profit purposes providing that:

- The full-text is not changed in any way

- A full bibliographic reference is made

- A hyperlink is given to the original metadata page in eResearch

eResearch policies on access and re-use can be viewed on our Policies page:

http://eresearch.qmu.ac.uk/policies.html

\section{Copyright $(\subset$ and Moral Rights for this article are retained} by the individual authors and/or other copyright owners.

\author{
http://eresearch.qmu.ac.uk
}




\title{
Rural versus urban accent as an influence on the rate of speech
}

\author{
NigEL HEWLETT AND MONICA RENDALL \\ Department of Speech and Language Sciences, Queen Margaret University College \\ Clerwood Terrace Edinburgh EH12 8TS UK \\ e-mail:n.hewlett@sls.qmced.ac.uk
}

\begin{abstract}
Speakers of rural accents have been said to speak more slowly than speakers of urban accents. However, there would appear to have been no previous empirical investigation of such a claim. In the study reported here, recordings were made of 12 Orkney English speakers and 12 Edinburgh English speakers, during a reading task and in conversation with the experimenter. Measurements, in syllables per second, were made of both the Speaking Rate and the Articulation Rate (i.e. the rate calculated after excision of pauses) of each speaker in reading mode and in conversation mode. Comparison of the results for the two groups revealed no tendency for the urban (Edinburgh) speakers to speak faster than the rural (Orkney) speakers. The claim that rural speakers speak more slowly than urban speakers therefore still awaits empirical support. Some discussion is offered concerning the possible relationships among speech tempo, lifestyle and accent.
\end{abstract}

\section{Introduction}

Speech rate of rural versus urban accents of English

In his comprehensive work on English accents, John Wells observes that "[i]t is perhaps universally true that rural accents tend to be slower in tempo [than urban ones] reflecting the unhurried life of the countryside" (Wells 1982: 11), adding in a later chapter that "to state the existence of this tendency is to make an impressionistic claim rather than to report a substantial fact. ... Particular urban or rural areas do not necessarily conform to it" (Wells 1982: 87). The latter, wisely cautious qualification both makes an empirical claim for such rural/urban differences more difficult to refute and complicates the task of explaining it if true (since the explanation would have to account for the tendency while at the same time allowing for the ability of some accents to buck the trend).

A further problem with addressing the claim empirically is that it remains unelaborated. The first quotation above implies that slower tempo is associated with the accent itself (regardless of the location or lifestyle of a given speaker?) but the effect is ascribed to speaker lifestyle ("unhurried life of the countryside"). For the purposes of the investigation reported here it was hypothesised (with due disregard for the escape clause contained in the second quotation from Wells, above) that native residents of the islands of Orkney, who speak with the local accent, should exhibit slower speech rates than native residents of the city of Edinburgh who also speak with their local accent. 


\section{Lifestyle and speech rate}

A study by Forsythe (1982) of the effects of urban migration to one of the Orkney islands contains reports from former urban dwellers that they did indeed experience a slackening of pace of life after moving to Orkney:

... you're not racing against the clock the way you seem to be in cities. (Couple 3) (p41)

Nobody ever hurries ... the first 3 or 4 months I wasn't used to the slow pace of living. (Couple 4) (p43)

... life up here is different ... There's no rush ... you're more relaxed up here. (Couple 5) (p46)

It is indeed perfectly possible that life in the countryside is more relaxed than life in the city. On the other hand it is possible that perceptions of the sort quoted above are heavily influenced by prior expectations and the preconceived notions of urban dwellers about rural life. We have nothing to say about how such a question could be addressed in a scientific fashion; that would be a matter for sociology rather than phonetics.

If some 'pace of life' difference between town and countryside could be identified, there still remains the question of precisely how a general aspect of lifestyle might exert an influence on the specific workings of the speech production apparatus. Attempts to investigate such questions scientifically are fraught with methodological problems. In a discussion which addresses the effects of emotional stress on speech, Murray, Baber and South (1996) conclude that the relationship between stress factors and features of the acoustic signal is "very unclear".

What is far less problematic however is to investigate the truth of the claimed outcome, namely that rural accents are slower than urban ones. This is a well defined question, eminently accessible to empirical investigation. There would be little point in speculating about how an unhurried lifestyle might impact upon the speech producing mechanism in advance of any finding that there was indeed a difference to be explained.

Besides being well defined, the claim addressed in this paper is, we believe, one that does indeed merit empirical investigation. Apart from the fact that it is in the form of a published claim by a serious researcher of language variety, it also appears to be a widespread belief, bolstered by many a performance on stage and screen, that rural speakers speak more slowly.

\section{Measurements of speech rate}

The overall rate of speech is influenced by the number and length of silent pauses and filled pauses ('Er', 'Um' etc.) which occur during utterances. It is obviously important in a comparative study of speech rate to compare both the overall rate (i.e. rate of speech with pauses included) and the rate of actual speech production (i.e. with pauses discounted). We use the term Speaking Rate for the former and Articulation Rate for the 
latter, following Goldman-Eisler (1956) and Laver (1994), except with respect to filled pauses which Laver includes in the calculation of Articulation Rate but which we include as part of the calculation of total Pause Time (see below). For the sake of clarity we use these terms, where (so far as we can ascertain) they seem appropriate, in discussing previous published work even though the authors themselves have not used them.

Speech rate has been measured mainly in syllables or words per unit time in previous studies. The most frequently used measure is syllables/second, which was the measure adopted in the present study. The syllable is preferable to the word as the unit of measurement because average word length might vary appreciably between one discourse and another, thus reducing comparability. Average syllable length is unlikely to exhibit as much variability, at least within the same language. Table 1 summarises the findings concerning normal, young to middle-aged adult speakers of English, of some previous research which used the syllable as the unit of measure. It suggests a Speaking Rate of something of the order of 3.5 to 5.0 syllables/second as the rate at which speech is normally produced. Malecot et al. (1972) report a tendency for Articulation Rate to increase with length of utterance. Goldman-Eisler (1968) reports variable Speaking Rates for her subjects for utterances ('speaking turns' in our terminology) of 40 syllables or less. Goldman-Eisler (1968) maintained that an increase in Speaking Rate could be ascribed to a decrease in Pause Time, with Articulation Rate remaining more or less constant. This finding was partially supported by a later study by Miller et al. (1984); they did also, however, observe an increase in the actual Articulation Rate of their subjects at faster Speaking Rates. An investigation which examined a large number of subjects (Walker 1988) is not included in Table 1 since it used only the cruder measure of words rather than syllables, per unit time.

Table 1. Some previous research findings on English speaking adults' normal Speaking Rate for reading and conversation, measured in syllables per second.

\begin{tabular}{|c|c|c|c|c|c|}
\hline \multirow[t]{2}{*}{ Author(s) } & \multicolumn{3}{|c|}{ Subjects } & \multicolumn{2}{|c|}{ Results } \\
\hline & Number & $\begin{array}{l}\text { Age } \\
\text { range } \\
\text { (years) }\end{array}$ & Accent & $\begin{array}{l}\text { Reading } \\
\text { (sylls/sec) }\end{array}$ & $\begin{array}{l}\text { Conversation } \\
\text { (sylls/sec) }\end{array}$ \\
\hline $\begin{array}{l}\text { Duchin \& } \\
\text { Mysak, } 1987\end{array}$ & 15 & $21-30$ & $\begin{array}{l}\text { American } \\
\text { English }\end{array}$ & 4.69 & 3.94 \\
\hline $\begin{array}{l}\text { Ramig, } \\
1983^{*}\end{array}$ & 8 & $26-35$ & not stated & 4.12 & 3.62 \\
\hline $\begin{array}{l}\text { Ramig, } \\
1983^{*}\end{array}$ & 8 & $25-38$ & not stated & 4.41 & 3.89 \\
\hline $\begin{array}{l}\text { Goldman- } \\
\text { Eisler, } 1968\end{array}$ & 4 & not stated & not stated & $\mathrm{n} / \mathrm{a}$ & $4.15^{*}$ \\
\hline
\end{tabular}

" Ramig (1983) investigated the effect of physiological condition on speech rate. The first group in the 26 35 age group are the subjects in 'good physiological condition'. The second group, in the age range of 25 38 years are the subjects in 'poor physiological condition'.

* Goldman-Eisler (1968) gave individual speech rates for the 4 subjects. In this table the results are averaged over the four subjects. The figures have also been converted from syllables/minute to syllables/second. 
There would appear to be a tendency for read speech to be slightly faster than spontaneous speech, although it is particularly important to consider the contribution of pauses here and to bear in mind the distinction between Speaking Rate and Articulation Rate (cf. Klatt 1976). Walker (1988) also found faster Speaking Rates for reading than for conversation.

With regard to extralinguistic influences on speech tempo there is some evidence for changes over the lifespan of the individual. Young children's rates tend to be significantly slower than those of adults, a fact which is thought to reflect immaturity of speech motor control (Waters 1992). And a slight decrease has been found in elderly speakers as compared with younger and middle-aged subjects (Ramig 1983; Duchin and Mysak 1987). Walker (1988) found no evidence of a difference according to gender in her study. Malecot et al. (1972) found no evidence that emotional state influences speech rate.

The data reported here are measurements of the speech rates, during both reading and conversation, of two groups of Scottish English speakers: one from a rural setting, the islands of Orkney, and the other from an urban setting, the city of Edinburgh. They are offered as a contribution on the question of the relationships among speech tempo, accent and lifestyle and, more generally, as an addition to the published information available on speech rate in English.

No previous study of speech rate has, to our knowledge, included accent as a variable. The investigation reported here sought to compare a group of young adult speakers with a rural accent and a rural family background with another group of young adults who spoke with an urban accent and came from an urban family background.

\section{Method}

\section{Subjects}

The Orkney group comprised 12 subjects of between 15 and 18 years of age ( 5 male and 7 female). They all spoke with an Orkney accent; they had lived all their lives on Orkney; and each subject's parents, as well as all four grandparents, were born and raised in Orkney. The Edinburgh group comprised 12 subjects ( 6 male and 6 female), also between 15 and 18 years, for whom similar selection criteria, mutatis mutandis, were applied. None of the subjects had any history of speech/language problems. The mean age of the Orkney subjects was $17 ; 6$ years and that of the Edinburgh subjects was $16 ; 8$ years.

\section{Data collection}

Each subject read aloud the first paragraph of the Rainbow Passage (Fairbanks 1960). They were then engaged in several minutes of conversation with the experimenter (who was a native Orkney speaker, with four years residence in Edinburgh). Each conversation spanned a small number of topics (usually two or three), for example family background, future career plans, hobbies or sports. The sessions with the 
Edinburgh subjects were conducted in the recording studio in the Department of Speech and Language Sciences, Queen Margaret University College. All the data was recorded using a PZM.microphone connected via a Mic-Amp Pak 2TM to a Sony DTC-690 Digital Audio Tape recorder. The sessions with the Orkney subjects were conducted in the Attic Recording Studio in Orkney and recorded using a Neuman U87 microphone via a soundtrack mixing console onto a Sony 1000ES Digital Audio Tape recorder.

\section{Analysis}

Temporal measurements were made from on-screen spectrographic displays using the Loughborough Sound Images (LSI) speech analysis software. The Speaking Rate in the reading mode, for each speaker, was calculated by measuring the time taken to read the entire paragraph (the Speaking Time), in seconds, and dividing it by the total number of spoken syllables, yielding a score for Speaking Rate in syllables per second (syllables/s). In the case of the conversational data, the investigator's speech was ignored and only the subject's speaking turns were analysed; of these, only speaking turns amounting to more than ten syllables were included. The Speaking Rate was then calculated in similar fashion to that for reading, for each speaking turn and for the total of all speaking turns by each speaker.

Calculation of Articulation Rate required the identification and measurement of all pauses in both sets of data. Any silent interval of $200 \mathrm{~ms}$ or more was counted as a pause. 'Hesitation fillers', such as 'eh', 'em', or laughter etc., were counted as filled pauses. The total time taken by all such pauses was defined as the Pause Time. An Articulation Time was calculated for each speaker in each speech mode (i.e. reading or conversation), by subtracting the Pause Time from the Speaking Time. Disfluencies were treated as follows. The disfluent articulation (repeated segment or syllable, for example) was counted as part of Articulation Time, while any silent interval of $200 \mathrm{~ms}$ or more adjacent to it was counted as a pause.

Thus, each subject's Speaking Rate and Articulation Rate were calculated, for both reading and conversational speech. In addition, the total Pause Time by each subject in each speech mode was expressed as a percentage of Speaking Time. Group means and standard deviations were obtained and statistical analysis was carried out with a view to ascertaining whether or not there was a significant difference between the two subject groups with respect to Speaking Rate or Articulation Rate in either of the two speech modes.

\section{Results}

Table 2 shows the mean scores for Speaking Rate and Articulation Rate for the two groups in each mode (reading and conversation).

\section{Speaking Rate}

In reading mode, the Orkney and Edinburgh subjects showed little difference in Speaking Rate (4.50 syllables/s and 4.55 syllables/s, respectively). The Orkney group's 
Speaking Rate in conversation (4.53 syllables/s) was very similar to that in reading. The Edinburgh group were slower in conversation mode (4.34 syllables/s), but the difference was not significant.

\section{Articulation Rate}

While there was little difference between the two groups in reading mode, the Orkney group was markedly faster in conversation than the Edinburgh group (6.02 syllables/s as compared with 5.52 syllables/s). Levene's test ( $t$-test for independent samples) indicated that in this case the difference was significant $(\mathrm{p}<0.01)$.

\section{Pause Time}

Despite the Orkney group's faster Articulation Rate in conversation, their overall Speaking Rate in this mode was not significantly faster, which implies that their conversational utterances must have contained relatively more Pause Time. This is confirmed by inspection of Table 2 . The Orkney group had a percentage Pause Time $5 \%$ greater than that of the Edinburgh group in the conversation mode. Thus the Orkney speakers' faster articulation rate in this mode was (so to speak) largely compensated by more pausing.

Table 2. Mean speech rates of rural (Orkney) and urban (Edinburgh) subjects. The values for Articulation Rate and Speaking Rate (for definitions, see the text) are in syllables per second, with standard deviations given in brackets beneath. Mean Pause Times, in the final row, are given as a percentage of the corresponding total Speaking Time.

\begin{tabular}{|c|c|c|c|c|}
\hline & \multicolumn{2}{|c|}{ Reading } & \multicolumn{2}{|c|}{ Conversation } \\
\hline & Orkney & Edinburgh & Orkney & Edinburgh \\
\hline $\begin{array}{l}\text { Articulation } \\
\text { Rate }\end{array}$ & $\begin{array}{l}5.49 \\
(0.47)\end{array}$ & $\begin{array}{l}5.43 \\
(0.41)\end{array}$ & $\begin{array}{l}6.02 \\
(1.12)\end{array}$ & $\begin{array}{l}5.52 \\
(0.82)\end{array}$ \\
\hline Speaking Rate & $\begin{array}{l}4.50 \\
(0.47)\end{array}$ & $\begin{array}{l}4.55 \\
(0.37)\end{array}$ & $\begin{array}{l}4.53 \\
(1.31)\end{array}$ & $\begin{array}{l}4.34 \\
(0.95)\end{array}$ \\
\hline Pause Time (\%) & 18.1 & 16.2 & 29.1 & 24.1 \\
\hline
\end{tabular}

\section{Length of speaking turns}

The conversation data consisted of natural dialogue between experimenter and subject. None of the subjects engaged in extensive monologue and there was a reasonably brisk interchange of speaking turns. However, the Edinburgh subjects tended to have longer speaking turns than the Orkney subjects and thus longer overall speaking times. Total speaking times (over turns of more than ten syllables) ranged from 3497 seconds (mean $=56$ seconds) for the Orkney speakers and 45-223 seconds (mean = 96 seconds) for the Edinburgh speakers (the subject with 223 seconds total speaking time was an outlier.) Therefore as a test of the robustness of the results the speech rates were further compared by matching them for length of speaking turn. Each speaking turn in the conversational data of each subject was categorised according to its length and the 
scores of the groups compared within each category. Only the first four categories (those spanning utterances between 10 and 50 syllables in length) contained substantial numbers of speaking turns. The overall trend of the results, with respect to differences between the two subject groups in Speaking Rate and Articulation Rate, was preserved in these categories.

\section{Discussion}

The values for Speaking Rate for both of the groups in this study are broadly similar to those of previous studies (see Table 1, above). As regards Articulation Rate, there is comparatively little published data for English. Laver (1994:158) quotes 5.3 syllables/second as a "medium articulation rate". Duez (1982) found a mean Articulation Rate of 5.2 syllables/second for a group of prominent French politicians in "casual interviews' and Malecot et al. (1972) found a Speaking Rate of 5.95 syllables/second for a group of Parisian French speakers. These are quite similar to the results for the English speakers in the present study, although as Laver (1994) points out, a measure of syllables per unit time is not a good basis for comparison of rate across languages because of possible differences in syllable structure.

With regard to the influence of reading versus conversation on rate, our results are perhaps a little surprising in that the differences in Speaking Rate, for both groups, were small. The Edinburgh group did have a slightly faster Speaking Rate for reading than for conversation, while for the Orkney group the Speaking Rate for reading was marginally slower, results that are in contrast to those of Duchin and Mysak (1987), Ramig (1983) and, notably, Walker (1988), who all found reading to be faster. With respect to Articulation Rate, both groups were faster in conversation than in reading, considerably so in the case of the Edinburgh group. Suppose, as our results suggest, that conversation has a tendency towards (if anything) a faster Articulation Rate than that for reading. Conversation is also liable to have a relatively greater amount of time devoted to pausing, as all studies including the present one agree. In conversational speech a longer speaking turn may well promote a larger percentage Pause Time, particularly if there is some onus on the speaker to continue speaking without the benefit of interruption from an interlocutor. This may be the explanation for the slower Speaking Rates found by Walker (1988) for conversation as compared with reading (her subjects were asked to speak "as if in conversation with the experimenter" (Walker 1988:14)). Speech rate differences (using both Speaking Rate and Articulation Rate measures) in different speech modes would be a fruitful subject for further investigation.

With regard to the central claim under investigation, the results fail to support the hypothesis that a rural accent is slower than an urban one. Of course, the speech rate of any speaker varies to some extent and a host of factors, such as researcher's accent, length of conversation or number of different topics it contained, might conceivably have influenced the outcome of this experiment. However, even admitting the possibility that in this experiment a real urban-rural difference was obscured (and reversed, as it would be, with respect to Articulation Rate) by the effect of an uncontrolled variable, the least 
one can say is that any influence from rural versus urban background on speech rate is not robust.

The results of this investigation, then, are cause for scepticism concerning an influence from geographical environment on speech tempo. The possibilities for individual variation are presumably situated within universal constraints on variation in speech tempo, due to biological and cognitive factors of speech production and communication (cf. Lindblom 1983: 217). The general question as to whether different accents do have characteristically different speech tempos (which could imply a 'linguistic element' in speech tempo) might in the end prove a more interesting one for phonetics than dealing with questions of the influence of lifestyle. A large number of studies of the kind reported here will be needed in order to establish whether or not speech rate varies systematically according to accent.

\section{References}

DUCHIN, S.W. \& MYSAK, E.D. (1987). Disfluency and rate characteristics of young middle-aged, and older males. Journal of Communication Disorders 20, 245-257.

DUEZ, D. (1982). Silent and non silent pauses in three speech styles. Language and Speech 25, 11-28.

FAIRBANKS, G. (1960). Voice and Articulation Drillbook. New York: Harper.

FORSYTHE, D. (1982). Urban-Rural Migration, Change and Conflict in an Orkney Island Community. London: Social Science Research Council.

GOLDMAN-EISLER, F. (1956). The determinants of the rate of speech output and their mutual relations. Journal of Psychosomatic Research 1, 137-143.

GOLDMAN-EISLER, F. (1968). Psycholinguistics: Experiments in Spontaneous Speech. London: Academic Press.

KLATT, D.H. (1976). Linguistic uses of segmental duration in English: Acoustic and perceptual evidence. Journal of the Acoustical Society of America 59, 1208-1221.

LAVER, J. (1994). Principles of Phonetics. Cambridge: Cambridge University Press.

LINDBLOM, B. (1983). Economy of speech gestures. In P.F. MacNeilage (ed) The Production of Speech. New York: Springer-Verlag.

MALECOT, A., JOHNSON, R. \& KIZZIAR, P.A. (1972). Syllabic rate and utterance length. Phonetica 26, 235-251.

Miller, J.L., GROSJEAN, F. \& LOMANTO, C. (1984). Articulation rate and its variability in spontaneous speech: A reanalysis and some implications. Phonetica 41, 215255.

MURRAY, I.R., BABER, C. \& SOUTH, A. (1996). Towards a definition and working model of stress and its effects on speech. Speech Communication 20, 3-12.

RAMIG, L.A. (1983). Effects of physiological aging on speaking and reading rates. Journal of Communication Disorders 16, 217-226.

WALKER, V.G. (1988). Durational characteristics of young adults during speaking and reading tasks. Folia Phoniatrica 40, 12-20. 
WATERS, D. (1992). An investigation for motor control for speech in phonologically delayed children, normally developing children and adults. PhD Thesis, Queen Margaret College, Edinburgh.

WELLS, J.C. (1982). Accents of English. Volume 1. Cambridge: Cambridge University Press. 